\title{
Varejo multicanal
}

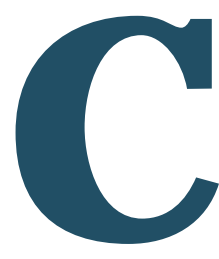

resce o número de empresas brasileiras que disponibilizam vários canais para a comercialização de seus produtos e serviços. No varejo, apesar de a prática não ser recente, o uso do comércio eletrônico via Internet vem se apresentando como estratégia para as empresas ampliarem sua inserção no mercado. 0 artigo discute os desafios da gestão do varejo multicanal e aponta que, se de um lado, ele traz vantagens competitivas, de outro, representa um desafio para as empresas que 0 adotam.

\section{por Roseli Morena Porto FGVEAESP}

Na década de 1990, com o surgimento das empresas atuando exclusivamente na Internet, previa-se que as Iojas físicas iriam desaparecer. Entretanto, observamos um movimento inverso: a adoção, também por empresas de varejo tradicional, do canal eletrônico. Essas empresas parecem ter descoberto, mais recentemente, a existência de sinergias entre os canais físico e virtual. A princípio, a adoção da Web como estratégia de venda ocorreu sem que essas empresas soubessem claramente as razões, exceto o desejo de estar preparadas caso o negócio vingasse. Com o estouro da bolha das ponto.com no final dessa mesma década, no entanto, muitas empresas pura- 
mente virtuais desapareceram, ao passo que as tradicionais não só continuaram, mas também intensificaram 0 uso da rede.

No início, a entrada dos varejistas no multicanal ocorreu de várias formas: comercialização via site independente puramente virtuais (Toy's R Us com a Amazon), aluguel de espaço em provedores de acesso e conteúdo (IG, MSN, UOL) e adesão a programas de visibilidade em agregadores de lojas, os chamados shopping centers virtuais (ShopFácil). Os varejistas de "cimento-e-tijolo" começaram assim uma luta contra os que atuavam somente na multicanal a fim de atingir os consumidores tanto por meios físicos como el etrônicos em múltiplas rotas de compra. Esse processo teve como conseqüência a consolidação do varejo multicanal como nova estratégia competitiva para as empresas varejistas. (Livraria Cultura, Saraiva), em alianças com varejistas Internet, adotando inovadoras estratégias de varejo

No Brasil, devido à inflação, o formato de catálogo não se desenvolveu. A rápida alteração de preços deixavao desatualizado logo que era distribuído. Esse fato ajuda a explicar, em parte, a resistência do consumidor brasileiro em compras inteiramente virtuais. A falta de infra-estrutura logística para a entrega, bem como meios de pagamento pouco desenvolvidos que dificultam o processamento ea confirmação do pedido antes da entrega do produto, também agravaram o quadro. Como conseqüência, o varejo multicanal no Brasil limita-se à loja física e a um site comercial na Internet.

Integração entre canais. 0 relacionamento entre a loja física e a loja virtual é estreito. Pesquisas têm constatado que a primeira tem o efeito de aumentar as vendas na segunda. Com isso, redes de lojas já constituídas têm grande vantagem competitiva, pois já são referência para o consumidor, que, em conseqüência, se sente mais confiante para comprar no respectivo site. Isso ocorre porque, para o consumidor, independentemente do meio, a transação está sendo realizada com uma "empresa real". A vantagem da compra pelo site envolve facilidades na pesquisa de preços e de acesso a informações sobre o produto.

Adicionalmente, a integração dos canais afeta positivamente a lealdade à marca e o lifetime value do cliente. Segundo pesquisas da Forrester Research, os varejistas que conseguem sincronizar a experiência de compra entre os canais,

Varejo multicanal pode ser definido como a oportunidade, dada ao consumidor, de obter o mesmo produto, de um mesmo varejista, por meio de múltiplos canais de compra. Assim, além dos vários formatos de loja (especializada, supermercado, hipermercado), alguns autores chegam a identificar até dez tipos de canais (venda porta a porta, tel evendas, quiosques, TV H ome Shopping, TV interativa etc.), embora a maior parte dos estudos esteja focada basicamente em loja física, website comercial na Internet e catálogo impresso, respectivamente brick, click e print. harmonizando produtos, preços e serviços, conseguem maior participação de mercado, recuperando o espaço perdido para os Internet pure players. De forma análoga, pesquisa realizada pela consultoria BCG - Boston Consulting Group - com consumidores de seis países europeus confirma a existência de sinergias entre os canais on-line e off-line dos respondentes que usam a Internet como fonte de pesquisa. Assim, $85 \%$ compram no mundo físico os produtos e marcas identificados nos respectivos sites e 35\% compram nas lojas do varejista cujo site foi pesquisado. 
Na prática, porém, a integração de canais não é tarefa simples. Além do desafio de operar centrais de atendimento e websites 24 horas por dia, sete dias por semana, a complexidade da infra-estrutura de sistemas e de tomada de decisão aumenta muito em um ambiente multicanal. Questões como preço de mercadorias, logística de entrega de produtos e opções de ofertas são al guns exemplos dos desafios com os quais as empresas que adotam múltiplos canais devem lidar a fim de aproveitar a sinergia entre os canais. Vejamos, a seguir, como as empresas podem lidar com esses desafios.

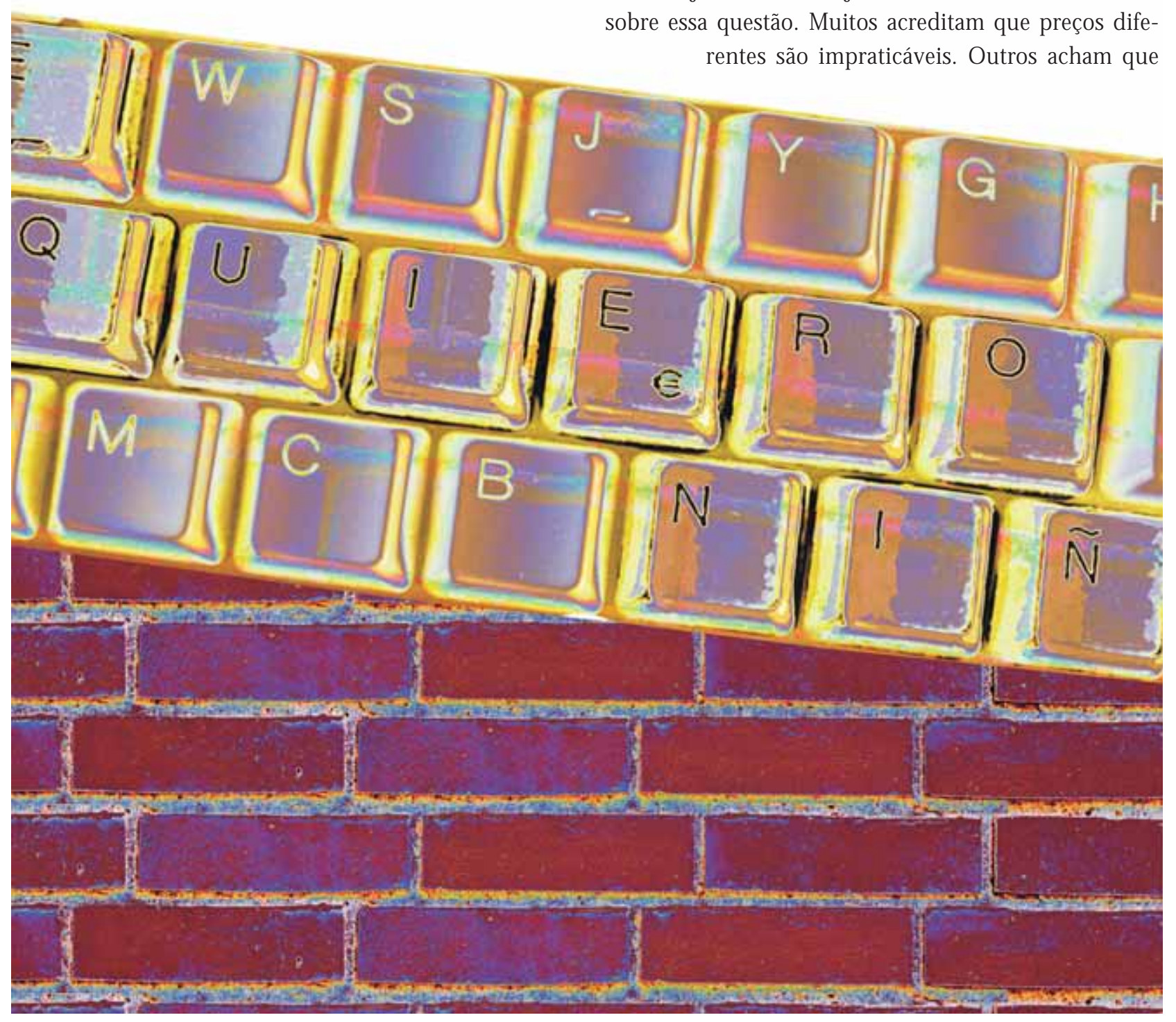

Política preço. De acordo com pesquisa do BCG, preços menores são o maior incentivo para os compradores on-line aumentarem suas compras. Além disso, o varejo virtual possui o efeito de aumentar a concorrência devido à facilidade que o consumidor tem em fazer pesquisa para comparação de preços, principalmente com a utilização de sites de busca. Pesquisas indicam que, se 0 frete for gratuito, os consumidores também compram mais.

O bviamente, a questão que pode ser levantada aqui é como estimular a compra on-line por meio de redução de preços se, ao mesmo tempo, é preciso garantir rentabilidade. As empresas deveriam praticar preços diferentes na loja física e na loja virtual? Não existe consenso sobre essa questão. Muitos acreditam que preços diferentes são impraticáveis. Outros acham que 
preços iguais são irrealistas, pois os clientes off-line devem, inevitavelmente, pagar mais pela satisfação da experiência de compra na loja.

0 fato é que os clientes esperam preços competitivos. Para eles, não importa em qual website compram, seja este um Internet pure player ou um canal on-line que é parte integrante de uma operação mais ampla de multicanal de uma rede física. Na prática, observa-se que as emp resas freqüentemente colocam preços menores na Internet, "compensando-os" nos canais convencionais. 0 problema surge quando, e se, o cliente leva à loja as informações impressas contidas no site. Para evitar esse tipo de constrangimento, a loja deve informar claramente ao cliente sobre os distintos preços que pratica.

Sorti mento de produtos. As decisões de política de produtos estão relacionadas com o sortimento e o tipo de produto. Qual deve ser o sortimento dos produtos no catálogo, na loja e na Internet? Quais os tipos de produtos que mais interessam aos internautas? de escolha disponíveis no catálogo impresso e na loja.

Todavia, os clientes podem ficar frustrados com a diferença no sortimento dos produtos ofertados nos canais. Mesmo assim pode haver razões comerciais justificáveis para as empresas manterem a limitação. Entre elas, podemos citar os custos de entrega e o risco de o cliente escolher produtos de forma incorreta, o que levaria a taxas de devolução eventual mente muito altas. N esse caso, uma sugestão seria que as empresas iniciassem com produtos de alto giro, primeiro focando na profundidade de sua principal categoria de produtos, para depois ampliála por meio da adição de produtos complementares. Finalmente, depois de conseguirem massa crítica, devem introduzir categorias e serviços diferenciados, tanto online como off-line, que tanto podem ser posicionados como claramente diferentes.

I ntegração de informações. A experiência de grandes empresas bem-sucedidas, como a maior rede varejista francesa de venda por catálogo, La Redoute, mostra que elas utilizavam a estrutura de suas lojas para promover o catálogo. N estas, o catálogo estava disponível para consulta logo na entrada com um sortimento muito maior. 0 cliente podia fazer o pedido na loja optando por retirá-lo lá mesmo ou então recebê-lo em casa. Pedindo por telefone, poderia escolher em qual loja retirar a mercadoria ou receber em domicílio. Essa prática foi mantida com a implantação de seu site transacional.

Para isso ser possível, é necessário que a base de dados do cliente e seu histórico de relacionamento sejam centralizados. Além disso, as informações dos clientes devem transitar de forma eficaz entre o canal em que a transação foi realizada e o canal em que será entregue a mercadoria. No varejo bancário isso já é uma realidade, pois ali se consegue identificar e consolidar, no extrato da conta corrente e para os vários canais (central de atendimento, Internet banking), se o cliente efetuou saque na agência, em um quiosque ou se fez uma compra com cartão de débito.

A decisão de integrar as operações deve ser tomada com base na solidez da infra-estrutura de distribuição e 
do sistema de informações já existentes, e na possibilidade de sua migração para o ambiente de Internet. O perações integradas promovem redução de custos, além de vantagem competitiva em relação aos concorrentes que atuam somente na Internet. Já as operações separadas deixam a empresa livre para criar o estado-da-arte, sistemas customizados sem as imperfeições dos antigos sistemas e desenvolver uma distribuição sofisticada e específica para a Internet, capaz de proporcionar uma melhor experiência de compra ao cliente.

Desse modo, em vez de focar em uma decisão de tipo "uma ou outra", os varejistas devem se interrogar: qual o grau de integração que mais faz sentido para a empresa? A decisão de integração-separação não deve ser uma escolha binária, pois existem infinitas combinações de integração para que as empresas personalizem suas estratégias nos dois ambientes, físico e virtual, de acordo com seu próprio mercado e situação concorrencial, aumentando, significativamente, a probabilidade de sucesso no e-business.

Atendi mento e distri bui ção. Se não for implantada ad equadamente, a estratégia de multicanal pode ter um efeito colateral muito prejudicial: a geração de conflitos internos. Um bom exemplo é o comportamento dos vendedores da loja em relação ao novo canal. Se eles sentirem que este último é uma ameaça, com certeza eles o boicotarão. Como forma de evitar essa resistência, já é comum as empresas repassarem parte do resultado da venda no site para a força de vendas.

M esmo assim, uma questão espinhosa permanece: os vendedores estão preparados para atender os clientes que encontraram um preço menor no site e querem finalizar a transação na loja? Eles têm autonomia para aplicar o preço do site? Outro aspecto importante é que o multicanal exige um aprimoramento das habilidades dos próprios vendedores, pois ele facilita 0 acesso às informações do produto, de modo que o consumidor chega mais informado à loja. É por essa razão que a empresa deve nivelar o conhecimento entre 0 site e a loja, estimulando, por exemplo, que sua força de vendas também utilize 0 site para consulta.

As empresas podem também facilitar ou dificultar 0 acesso dos clientes aos tipos e quantidade de informações disponibilizadas no Website, em comparação aos canais convencionais, com o objetivo de refinar a segmentação de consumidores. Os sites de livrarias, por exemplo, são ricos em informações como resenhas de livros, lista dos mais vendidos, sugestões de leitura, biografia e detal hamento da obra do autor, opinião de leitores etc.

Por fim, as empresas devem dar muita atenção aos aspectos relacionados à entrega do produto. Os consumidores punem os varejistas tradicionais que falham na operação on-line. Pesquisa do BCG identificou que, dos compradores que tiveram problemas em compras on-line, 35\% pararam de usar o website para pesquisar, 32\% deixaram de comprar e $6 \%$ não compraram mais na loja do varejista que falhou na Internet.

As evidências demonstram que o mercado multicanal é uma tendência que veio para ficar. No Brasil, como a experiência das empresas nesse mercado ainda é recente, importantes desafios permanecem em aberto, sobretudo referente à gestão de uma estratégia dupla. É preciso cuidar, como procuramos demonstrar neste artigo, para que ambas se potencializem mutuamente. 0 fato é agravado porque o cliente de um canal múltiplo éo mesmo cliente, muitas vezes atendido simultaneamente pelos dois meios de relacionamento. Por essa razão, é de se esperar grande investimento nesse campo nos próximos anos, além do desenvolvimento de modelos complexos de gerenciamento focados na busca de ganhos recíprocos entre os vários canais utilizados. É também possível imaginar que muitas empresas consolidadas entrem para o mundo virtual, maximizando assim o val or de suas marcas em mercados de consumidores cada vez mais informados e exigentes.

\section{Roseli Morena Porto}

Profa. do Departamento de Administração Geral e Recursos Humanos da FGV-EAESP

Pesquisadora do GVcev - Centro de Excelência em Varejo

E-mail: roseliporto@fgvsp.br 